\title{
SÉrgio BuARQue de Holanda E AS CiênClas Sociais
}

\author{
João Antônio de Paula
}

1

estes tempos de ultra-especialização, a obra o o exemplo de Sérgio Buarque de Holanda parecem momentos de uma heroicidade tão impressionante quanto rara. Crítico literário, professor de história e de literatura, historiador da cultura e da vida material, etnógrafo e historiador da política, Sérgio Buarque imprimiu a todos estes campos em que atuou a marca de uma lucidez impenitente, de uma erudição sólida e sábia. Nascido em 1902, em São Paulo, cidade em que também morreu, em 1982, Sérgio Buarque está entre os nomes mais significativos da nossa vida intelectual. A ele devemos, como a poucos, por sua generosidade e pelo muito que ensinou a gerações de brasileiros. Homem do seu tempo não se recusou a enfrentar os desafios postos pela vida política e nestes engajamentos escolheu sempre o lado democrático e popular. Modernista de primeira hora, atualizou-nos, também, no referente às vanguardas internacionais e às ciências sociais. Sua obra, nas páginas de jomais e revistas, na docência, nos livros, nos cargos de instituições culturais que dirigiu, é desses testemunhos sempre necessários, de que a inteligência pode ser colocada, livre e absolutamente, a serviço do bem comum, da solidariedade e da alegria, que nele eram abundantes.

Em texto de 1992, Francisco Iglésias apontava o lugar importante que a crítica historiográfica ocupa na obra de Sérgio Buarque, destacando os trabalhos constantes dos volumes Cobra de Vidro e Tentativas de Mitologia, além da contribuição de Sérgio para o Manual Bibliográfico de Estudos Brasileiros, organizado por Rubens Barbosa de Morais e William Berrien, no qual foi responsável pela apresentação crítica da bibliografia sobre o período colonial. É também de Iglésias a observação sobre 0 significativo da intervenção de Sérgio Buarque no campo da crítica historiográfica contida nos vários prefácios que escreveu para livros de história. ${ }^{2}$

1 Doutor em História pela Universidade de São Paulo. Professor Titular do Cedeplar - FACE/UFMG. É autor dos livros: Presença de Francisco Iglesias e Economia Política na Mudança, ambos pela editora Autêntica. 2 Igrésias, E. "Sérgio Buarque de Holanda, Historiador". In: $3^{\circ}$ Colóquio UERJ-Sérgio Buarque de Holanda. Bastos, F. I. P. (Org.). Rio de Janeiro: Imago, 1992. p. 40. 
Em 1996 foi publicado o Livro dos Prefácios, com o conjunto dos prefácios elaborados por Sérgio Buarque de Holanda. Também de 1996 são os dois volumes de $O$ Espirito e a Letra, organizados por Antonio Arnoni Prado, contendo artigos de crítica literária de Sérgio Buarque publicados entre 1920 e 1959. ${ }^{4}$ Em 1991, organizado por Antonio Candido, foi publicado Capítulos de Literatura Colonial, livro inédito e incompleto, escrito a partir de ampla pesquisa realizada na Itália, entre 1952-54, e que tem como objeto central a Escola Arcádica, contendo, também, em apêndice, um luminoso texto sobre 0 Padre Vieira. ${ }^{5}$ Todo este vasto material publicado postumamente não esgota a produção de Sérgio Buarque.

Neste texto vai-se defender que a excelência da crítica historiográfica de Sérgio Buarque de Holanda, decorre de sua original e superior apropriação de três grandes matrizes intelectuais: 1) o modernismo literário, tanto em sua visão internacional, quanto em sua recep̧̧ão e reinvenção nacional da qual ele foi protagonista como crítico literário, a partir de 1920;2) as "ciências do espírito", marcadas por influências variadas, por um arco excêntrico, que vai de Dilthey a Huizinga, passando por De Sanctis e Croce até a estilistica alemã de Vossler, Spitzer, Auerbarch e Curtius, à sociologia histórica de Simmel, Weber e Sombart; 3) finalmente, a história, entendida como campo abrangente, globalizante, que inclui tanto a economia, quanto a política, as idéias e as artes, os hábitos e o cotidiano, num projeto que é gestado ao mesmo tempo e com grandes afinidades com o da École des Annales, em sua primeira fase.

Toda esta ampla e profunda gama de referências foi mobilizada por Sérgio Buarque sem mitificações ou subalternidade. Ele mostrou que a grande cultura podia, e pode, quando adequadamente apreendida, ser um instrumento revelador de aspectos importantes de nossa realidade. Sérgio Buarque mostrou que categorias analíticas relevantes, quando dotadas de efetiva universalidade são tão nossas quanto de todos. Em sua obra, quase como um leitmotiv, Sérgio Buarque buscou compreender as determinações de um processo, a gênese e o desenvolvimento da modernidade e do capitalismo, que reservou a cada um dos seus participantes lugares específicos, constrangimentos e virtualidades, que acabaram por significar relações assimétricas de poder econômico, político e cultural entre os países.

Sérgio Buarque de Holanda contribuiu para atualizar nossa vida cultural, revelounos significativos autores e idéias estrangeiros. Seu papel, neste sentido, assemelha-se ao

3 Holanda, S. B. de. 0 Livro dos Prefácios. São Paulo: Companhia das Letras, 1996.

4 Holanda, S. B. de. O Espírito e a Letra. São Paulo: Companhia das Letras, 1996. (2 vols.)

5 Holanda, S. B. de. Capítulos de Literatura Colonial. São Paulo: Brasiliense, 1991. 
dos grandes emigrados para o Brasil-0tto Maria Carpeaux, Paulo Rónai, Anatol Rosenfeld, Herbert Caio - a quem devemos muito. Mas, Sérgio Buarque de Holanda não foi apenas alguém que nos trouxe o distante, as vanguardas e a alta cultura, foi também um "obstinado" pela história do Brasil, como ele mesmo disse certa vez.

\section{Sérgio Buarque E a Historiografia Brasileira}

Desde a já clássica interpretação de Antonio Candido, em prefácio à quinta edição de Raízes do Brasil, de 1969, que Sérgio Buarque foi consagrado como um dos três mosqueteiros da renovação historiográfica brasileira, junto com Gilberto Freyre e Caio Prado Jr. 0 essencial desta renovação seria tanto o referente aos métodos de interpretação - o culturalismo de Gilberto Freyre, o weberianismo de Sérgio, o marxismo de Caio Prado - quanto, mais decisivo, as perspectivas que animam aquelas obras e teriam redescoberto o Brasil no sentido de pensá-lo sem as peias do preconceito, sem ufanismos, mas, também, sem autopiedade. Para prolongar a metáfora, como no caso dos três mosqueteiros, também aqui não são eles apenas três. Devem ser considerados no mesmo rol renovador um Manoel Bonfim, um Fernando de Azevedo.

O sentido distintivo da obra destes renovadores de nosso pensamento social destacase por um duplo contraste: de um lado com relação à tradição derivada do Instituto Histórico e Geográfico Brasileiro, e de outro lado, por contrapor-se às tendências "cientificistas", à moda do século XIX, corrente heteróclita, que acolheu diversas perspectivas, de Tobias Barreto a Oliveira Vianna. Mas, não se veja nisso uma recusa em bloco destas correntes, que deram contribuição relevante à compreensão do Brasil. 0 que se quer sublinhar aqui é o ânimo renovador dos autores, que na década de 1930, à luz das transformações sócio-materiais que o país estava vivendo, atualizaram a maneira como nos víamos a nós mesmos, a partir dos avanços das ciências sociais de então. Trata-se, aqui, de reconhecer as várias e decisivas conseqüências da renovação das ciências sociais decorrentes da recepção de um novo repertório teórico-metodológico tributário das contribuições da sociologia funcionalista, da sociologia weberiana, do marxismo, das "ciências do espírito", da geografia humana de Vidal de la Blache, da École des Annales.

No caso de Sérgio Buarque de Holanda, a algumas destas correntes, que 0 influenciaram diretamente, deve ser acrescido um outro grande patrimônio referencial: o modernismo literário. Sérgio Buarque desenvolverá sua atividade como crítico literário a partir de 1920 , pari passu com o próprio desenvolvimento de 
nosso modernismo, do qual ele foi "representante" no Rio de Janeiro, onde morava então. A década de 1920 será para Sérgio Buarque de Holanda um tempo de crítica literária. Até sua viagem para a Alemanha, em 1929, foi à literatura que Sérgio se dedicou, funcionando, naquele momento, no conjunto do movimento modernista, como um dos seus mais característicos críticos.

João Luiz Lafetá dedicou livro importante aos críticos da época modernista, Alceu Amoroso Lima, Agripino Grieco e Mário de Andrade. ${ }^{6}$ Destes, Agripino Grieco (1888-1973) tem posição singular porque iniciou sua carreira no pré-modernismo e jamais perfilou qualquer "método crítico" sendo movido antes por erudição segura e ânimo crítico, algo desabusado, como se vê em sua antipatia militante para com a obra de Machado de Assis. Mário de Andrade e Tristão de Ataíde, nascidos no mesmo ano, 1893, são os grandes críticos modernistas, sendo que Tristão, desde 1919, já dava mostras de uma cultura sólida e juízo crítico equilibrado, formado pela influência de Croce, que 0 autor apreendera em sua estadia na Europa, antes de 1914.

Sérgio Buarque ligou-se aos dois, por amizade e interesses intelectuais comuns e, de alguma maneira, em sua atividade crítica, combinará aspectos derivados deles: de Tristão absorverá certa visão ampla, informada, em que a análise das obras e das circunstâncias está sempre balizada pela busca da compreensão do seu entorno filosófico e cultural; de Mário de Andrade veio-lhe a liberdade crítica, a inventividade, a paixão pelas coisas do Brasil.

Nos anos 1920 a busca de fundar uma historiografia com base no modernismo nãoé, ainda, a tarefa de Sérgio Buarque. Isto coube sobretudo a Paulo Prado, a Alcântara Machado e a Cassiano Ricardo Leite. Paulo Prado (1869-1943), vai publicar, em 1925, Paulística, livro que estuda o movimento das Bandeiras; em 1928, que étambém o ano da publicação de Macunaima, de Mário de Andrade, ele publicará seu livro mais conhecido, Retrato do Brasil, que é tentativa de ensaio de psicologia histórica, com muito pouco de ciências sociais e muito de imaginação ficcional. ${ }^{7}$

Alcântara Machado (1901-1935), é autor de uma obra no campo da história - Vida e Morte do Bandeirante, também de 1928 - que tem o sentido da antecipação de tendência que hoje se impõe como novidade. Trata-se do que se tem chamado de história do cotidiano. Com base em pesquisa de inventários, o livro recria 0 ambiente dos bandeirantes, sua cotidianidade - as moradias, o mobiliário, os utensílios domésticos, as vestimentas, os hábitos e costumes, a medicina e a

6 LAFETÁ, J. L. 1930: a crítica e o modernismo. São Paulo: Duas Cidades, 1974.

7 Prado, P. Província \& Nação. Paulística. Retrato do Brasil. Rio de Janeiro: José Olympio, 1972. 
justiça, a religião e a família. ${ }^{8}$ Veio de Alcântara Machado, e de seu professor Afonso de Taunay em seus Relatos Sertanistas, a motivação para os estudos monçoeiros de Sérgio Buarque de Holanda. 0 outro modernista-historiador a ser considerado aqui é Cassiano Ricardo Leite (1895-1974). Em 1942 ele publicou Marcha para Oeste, que busca fixar a expansão das Bandeiras para o Oeste, entre os séculos XVI e XVIII, numa perspectiva que tem algo de epopéia, de elogio da obra dos paulistas. ${ }^{9}$ Finalmente, lembre-se outro nome do modernismo, Sérgio Milliet (1898-1966), que ao lado da crítica literária, notabilizou-se também por seus estudos de crítica de artes plásticas, por traduções importantes (Montaigne, Rousseau), e por estudos de sociologia histórica em que se destaca o livro Roteiro do Café, de 1938.

Sérgio Buarque, nos anos 1920, não se dedicou à história. Toda a sua atuação voltou-se para a literatura e a ela se dedicou inteiramente, mobilizando neste esforço, já nos anos 1920, sua "cultura de opulência insondável", de que fala seu amigo e colega de geração, Pedro Dantas, (Prudente de Morais Neto).$^{10}$ Na tradição dos historiadores ligados ao Instituto Histórico e Geográfico, fundado em 1838, não era incomum que os historiadores se dedicassem, também, aos estudos literários, e mesmo praticassem versos e ficção. Varnhagen (1816-1878), cometerá seus versos, e deixou contribuição importante às letras brasileiras com os três volumes de seu Florilégio da Poesia Brasileira, que é precedido de: "Ensaio Histórico sobre as Letras no Brasil", publicado entre 1850 e $1853 .{ }^{.1}$ Joaquim Norberto (1820-1891), outro luminar do Instituto, também freqüentou as belas letras deixando romances, novelas, teatro e poesia, além do seu Bosquejo da História da Poesia Brasileira, publicado em $1840{ }^{12}$

Estes exemplos saídos da realidade brasileira, denotam uma proximidade entre a literatura e a história, que ainda se mantinha na época em que Sérgio Buarque formouse, e cujos grandes praticantes foram Dilthey, De Sanctis, Croce, Huizinga. Para estes autores o fenômeno cultural sempre foi entendido como fenômeno global, em que a história e as artes, a filosofia e as ciências, eram apreendidas em suas múltiplas determinações recíprocas. De tal modo que não terá causado maior surpresa a transição de Sérgio Buarque da crítica literária à história, primeiro como professor, na então Universidade do Distrito Federal, entre 1936 e 1959, de História Moderna e Econômica e

\& MAchado, A. Vida e Morte do Bandeirante. São Paulo: Martins, 1972.

9 Ricardo, C. Marcha para Deste. Rio de Janeiro: José Olympio, 1959. (2 vols.).

${ }^{10}$ Davtas, P. Apresentação da Edição Facsimilada da revista Estética (1924-25). Rio de Janeiro: Gernase, 1974. p. VIII.

${ }^{11}$ Varnhagen, F. A. Florilégio da Poesia Brasileira. Rio de Janeiro: Academia Brasileira, 1946. (Tomo I).

${ }^{12}$ Norberto, J. Bosquejo da História da Poesia Brasileira. Belo Horizonte: Editora UFMG, 1997. 
depois de História da América e Cultura Luso-Brasileira, como assistente de Henri Hauser, e de Literatura Comparada, como assistente do professor Henri Tronchon, e a seguir como historiador com seus livros: Raizes do Brasil, 1936; Monções, 1944; Caminhos e Fronteiras, 1957; Visão do Paraíso, 1958; a organização da História Geral da Civilização Brasileira, Colônia e Império, de 1960 a 1972, em que ao lado de ensaios decisivos, como o inexcedível - "Metais e Pedras Preciosas", publicou aquele extraordinário volume que é Do Império à República. ${ }^{13}$

Em 1928, seu amigo Alceu Amoroso Lima, escreveu-lhe carta, que ficou famosa por redefinir rumos, dividir águas, separando-os política e ideologicamente, até que a luta comum contra a ditadura militar os reunisse de novo na mesma trincheira. Esta carta que se intitulou "Adeus à Disponibilidade", significou para Tristão de Ataíde trilhar o caminho do ultramontanismo de Jackson de Figueiredo. ${ }^{14}$ Para Sérgio Buarque de Holanda aquele também foi momento de redefinições, o tempo de uma escolha definitiva - sua viagem e estudos na Europa, que significaram sua adesão integral ao ofício de historiador.

Entre as muitas classificações passíveis para apreender o fazer dos historiadores uma tem grande audiência. É a que separa, nafalta de melhores nomes, os "historiadores de arquivo", dos "historiadores de biblioteca". Nesta divisão é comum atribuir-se valor maior, e distinção, aos "historiadores de arquivo", os quais praticariam a verdadeira e legítima historiografia, a que decorreria do trabalho analítico sobre fontes primárias acreditadas capazes de revelar aspectos novos da realidade, porque inéditas. Essa distinção, quase sempre tomada como valor absoluto e inquestionável, acaba, na verdade, por restabelecer uma hierarquia das fontes, que, afinal, é um retrocesso em relação aos avanços decorrentes da "dessacralização" das fontes operada pela historiografia contemporânea. De outro lado, esta distinção acaba por não captar, de fato, os fazeres historiográficos no que têm de essencial. Afinal, o que caracteriza o trabalho do historiador é a circunscrição de seu discurso àquilo que as fontes permitem dizer, sejam ou tenham elas a forma, suporte ou gênero que tiverem - romances, documentos particulares, fotos, imagens, documentos empresariais ou públicos, etc.

Também significativo é reconhecer que os historiadores brasileiros têm, desde o século XIX - a partir de diferentes correntes e perspectivas -, trabalhado, indistintamente,

\footnotetext{
Hotanda, S. B. de. História Geral da Civilização Brasileira. O Brasil Monárquico, Tomo II, $5^{\circ}$ vol.; Do Império à República. São Paulo: Difel, 1972.

1. IciĹ:Sus, F. "Estudo sobre o pensamento de jackson de Figueiredo" In: História e ldeologia. São Paulo: Perspectiva, 1971.
} 
com materiais colhidos em arquivos e bibliotecas. Varnhagen é historiador de arquivose bibliotecas como o são Capistrano de Abreu e o nosso contemporâneo Sidney Chalhoub, que acaba de publicar livro sobre Machado de Assis, em que as fontes são a obra literária de Machado de Assis e a documentação do Ministério da Agricultura, no tempo em que Machado de Assis trabalhou ali. ${ }^{15}$

No plano internacional, merece destaque para o que se discute aqui, a obra de Carlo Ginzburg, por sua invulgar desenvoltura em transitar entre "livros de arquivos" e "livros de biblioteca" - no primeiro campo estão os clássicos Os Andarilhos do Bem,O Queijo e os Vermes e História Noturna; no outro campo as notáveis coletâneas de ensaios Mitos, Emblemas e Sinais, Olhos de Madeira e Relações de Força. E trazer Carlo Ginzburg para um trabalho sobre Sérgio Buarque de Holanda é mais que circunstancial: é que há linhas de convergência entre as duas trajetórias intelectuais, sobretudo quando se sabe da centralidade da literatura, da estilística, da história da cultura, da etnologia, da erudição enfim, na obra dos dois historiadores.

Em Sérgio Buarque de Holanda a superior capacidade de articular diversos universos conceituais e metodológicos foi forjada a partir de três grandes matrizes: o modernismo literário brasileiro do qual foi testemunho e sujeito de primeira hora; as "ciências do espírito", que ele absorveu em sua temporada européia entre 1929 e 1931; a história do Brasil na qual ele mergulhou definitivamente a partir da década de 1930.

Entre os historiadores brasileiros que se avizinham de Sérgio Buarque o nome a se destacaréo de Capistrano de Abreu (1853-1927). Esta vizinhança, esteparentesco intelectual existe tanto no referente à temática, quanto, sobretudo, no relativo ao "estilo", à forma. Nos dois casos, está-se diante de grandes eruditos, de pesquisadores dotados de extraordinária amplitude de conhecimentos e de qualidade de escrita refinadíssima. Ambos são mestres da língua, da elegância da frase e de uma acentuada acuidade crítica. Fazem lembrar um outro mestre do estilo - Graciliano Ramos. Sobre isto lembre-se um desconhecido texto de Sérgio Buarque - Viagem a Nápoles - um conto escolhido por Graciliano Ramos para figurar em coletânea-Contos e Novelas - que ele organizou para a Editora da Casa do Estudante do Brasil, publicada em 1957.

Capistrano de Abreu e Sérgio Buarque de Holanda deram-nos obras fundamentais sobre a História do Brasil. Há paralelismo significativo entre as duas obras. Capitulos da História Colonial, de Capistrano de Abreu, de 1907, obra de síntese, tem em Raízes do Brasil, de Sérgio Buarque, de 1936, uma espécie de duplo, porque animados, os dois livros, pelo mesmo espírito de síntese. O Descobrimento do Brasil, de Capistrano de

\footnotetext{
${ }^{15}$ ChalHoub, S. Machado de Assis Historiador. São Paulo: Companhia das Letras, 2003.
} 
Abreu, unindo trabalhos produzidos entre 1883 e 1910, tem seu equivalente na obra de Sérgio Buarque de Holanda, no notável livro que é Visão do Paraíso, de 1958. Nos dois casos, a pesquisa acurada, de documentação coeva, vai resultar em interpretação decisiva sobre as origens do Brasil. Noutro registro, Caminhos Antigos e Povoamento do Brasil, de Capistrano de Abreu, publicado postumamente, em 1930, e Monções, 1945, e Extremo Oeste, também livro póstumo, de 1986, são obras de geohistória, em que há busca da fixação do processo de formação do território brasileiro. Um outro campo de semelhança éo referente à etnografia. Sérgio Buarque publicou, em 1957, Caminhos e Fronteiras, que revela maestria no tratamento de temática etnográfica, que também foi cultivada superiormente por Capistrano de Abreu em vários trabalhos contidos nas quatro séries dos Estudos e Ensaios, em que se destacam as análises sobre lingüística indígena na terceira série dos Estudos e Ensaios..$^{16}$

Há outras afinidades. Ambos foram funcionários da Biblioteca Nacional, ambos começaram suas carreiras como críticos literários, ambos foram professores. Asepará-los, consta certa rispidez legendária do cearense, enquanto o paulista teria, inversamente, um bom humor e alegria também legendários. Estas diferenças de temperamento, contudo, não implicaram em diferenças de estilo literário, em modo de apresentação das idéias. Em ambos, prevalecem o rigor e a elegância, a inteligência crítica e a visão ampla e contextualizante, que é a maior virtude do historiador.

A crítica literária, já se disse, foi cultivada pelos dois autores com ênfase. Das quatro séries dos Ensaios e Estudos, a maior parte do material é sobre a temática literária. 0 equivalente em Sérgio Buarque de Holanda são os volumes - Cobra de Vidro, 1944; Tentativas de Mitologia, 1979; O Livro dos Prefácios, 1996; O Espirito e a Letra, 1996. Também aí a matéria literária ocupa lugar de destaque, sendo amplamente majoritária nos dois volumes de $O$ Espirito e a Letra.

Se a matéria literária é dominante, a crítica historiográfica tem forte presença nos livros aqui considerados, tanto de Capistrano, quanto de Sérgio Buarque. Na primeira série dos Ensaios e Estudos, de Capistrano, dos 13 artigos, 7 tratam de temas historiográficos: são dois artigos sobre Varnhagen; um artigo sobre a obra de Fernão Cardim acerca dos índios brasileiros; um artigo intitulado "Notas sobre a Paraíba", de Irineu Joffily; um artigo sobre a obra de Frei Manuel Calado, ou Manuel do Salvador, sobre a história das invasões holandesas em Pernambuco; a nota necrológica sobre Eduardo Prado destacando-o, sobretudo, por seus estudos sobre a história do Brasil e de Portugal; finalmente, há o texto decisivo, que é a introdução

\footnotetext{
${ }^{16} \mathrm{ABREu}$, J. C. de. Ensaios e Estudos — $3{ }^{\text {a }}$ série. Rio de Janeiro: Civilização Brasileira, 1976.
} 
de Capistrano aos Diálogos sobre as Grandezas do Brasil, em que ele contesta a autoria deste livro como sendo de Bento Teixeira.

A segunda série dos Ensaios e Estudos, (17 ensaios), é toda composta de estudos de crítica historiográfica. É também o caso da terceira série, (12 ensaios), em que aparecem os 3 ensaios de etnografia sobre os bacaeris e caxinauás. A quarta série, composta de 75 artigos de dimensões menores, tem matéria de crítica literária e de crítica historiográfica, em quase equilibrio. Registre-se, ainda, que grande parte dos ensaios de crítica literária de Capistrano foram escritos antes de 1883, quando, tendo vencido concurso para professor do Colégio Pedro II, vai se ocupar cada vez mais com os estudos de história, geografia, etnografia, etc. Assimé que, referente às temáticas, às áreas de maiores estudos e cuidados, as obras de Capistrano e Sérgio Buarque guardam grandes semelhanças.

Em Cobra de Vidro, segunda edição de 1978, dos 19 ensaios 5 tratam de matéria historiográfica, quais sejam: o panlusismo, a partir da obra de Gilberto Freyre; 0 extremo-sul do Brasil; a história da Companhia de Jesus do Padre Serafim Leite; a obra de "etnografia histórica" de Otoniel Mota; a obra de história da cultura do século XIX de Mario Praz, o "sábio professor da Universidade de Roma". Os quatorze artigos restantes, de Cobra de Vidro, tratam de temas literários. Em Tentativas de Mitologia, dos 17 ensaios, 8 são dedicados à crítica literária, 2 trabalham temas filosóficos, 5 abordam questões de ciências sociais, e 2 são especificamente de crítica historiográfica. 0 Livro dos Prefácios constitui-se de 24 artigos, todos sobre temática historiográfica, assim divididos: 15 prefácios de livros de história do Brasil; 6 prefácios sobre obras documentais sobre o Brasil, 2 prefácios sobre livros de história da América Latina; 2 prefácios de livros sobre historiografia. Finalmente, os dois volumes de 0 Espirito e a Letra, abrangem a produção de crítica literária, atividade a que Sérgio Buarque dedicou-se com algumas interrupções a partir de 1920.

Insistindo nas três afinidades partilhadas por Capistrano e Sérgio Buarque, uma primeira diz respeito às profundas ligações dos dois com a literatura. É o estudo, 0 permanente cuidado com a produção literária, que molda um dos aspectos centrais da acuidade crítica dos dois autores. A literatura, a ocupação sistemática com questões filológicas e de estilo, a sensibilidade desenvolvida pela atividade da crítica literária armou-os de um ponto de vista, de um instrumento analítico que traz ponderáveis resultados para o fazer historiográfico. É que os historiadores afeitos às coisas da análise estilística, à filologia, estão mais preparados para surpreenderem 0 anacronismo. 0 trato com a língua, a apreensão da dinâmica histórica do discurso capacita-os para a apreensão da diacronia, para a identificação da presença indesejada do anacronismo. 
Ao lado da já apontada contribuição da análise literária à crítica historiográfica, háum outro aporte decisivo da literatura, pois ela deu aos dois historiadores uma qualidade estilística superior: Capistrano e Sérgio Buarque são mestres escritores dos melhores entre os que escreveram em português, em qualquer gênero. Um segundo ponto a se destacar refere-se à maneira ampla com que o campo da história foi entendido e praticado pelos dois autores. A história para eles, a maneira como buscavam construir suas obras historiográficas, é materialização daquela definição de Marc Bloch - "A história é o estudo dos homens no tempo". E assim, estão lá, em suas obras, o que os homens pensaram, sonharam, projetaram, construíram...

Na verdade, é preciso reconhecer que o essencial do melhor da tradição da Escola dos Annales, a idéia da "história problema", da "história total", a denúncia do anacronismo, são questões que também foram partilhadas pelos historiadores brasileiros considerados aqui. Éo que se vê, por exemplo, no livro de Capistrano, O Descobrimento do Brasil, que tem como objeto central, não a atribuição definitiva da autoria e data do "descobrimento", mas, se se permite, as condições da possibilidade do descobrimento, isto é, a análise do contexto dos descobrimentos e os diversos significados, consequiências e interesses presentes no evento. Do mesmo modo, é também complexa e sutil a questão que Sérgio Buarque de Holanda propõe no referente às motivações ibéricas dos empreendimentos da conquista ultramarina, queéobjeto do seu livro Visão do Paraíso. Nos dois casos, longe se está da pretensão de tentar "descrever os fatos tais como eles ocorreram". É uma historiografia sóbria, crítica e "contemporânea", que se vê nestes trabalhos, os quais pelo método e fatura aproximam-se de clássicos consagrados como 0 Outono da Idade Média, de Huizinga, de 1919; Os Reis Taumaturgos, de Marc Bloch, de 1924; e O Problema da Descrença no Século XVI.A Religião de Rabelais, de Lucien Febvre, de 1942.

Finalmente, uma última afinidade - a profunda presença da cultura alemã na obra de Capistrano e Sérgio Buarque. Se em Capistrano a influência alemãé resultado da presença forte da Escola do Recife e seus mestres - Tobias Barreto, Silvio Romero - e significou o atrelamento a um patrimônio conceitual marcado por um "cientificismo" problemático, que fundiu Comte, Spencer, Darwin, Hackel, Ratzel, Gumplowicz, etc., em Sérgio Buarque a influência alemã vem por outras vias, émais aberta e plural, e teve um rendimento heurístico notável. Sérgio Buarque foi marcado pelo que se chamou aqui "ciências do espírito". 


\section{Sérgio BuARque E AS ClêncIAS do Espírito}

No final do século XIX, depois de uma relativamente curta hegemonia, o positivismo passou a ser questionado por um conjunto variado de perspectivas e autores, cujas raízes teóricas remontavam tanto a Kant quanto a Hegel. A palavra de ordem deste processo éa expressão "ciências do espírito", ou "ciências da cultura", e seus titulares são, de um lado, Wilhelm Dilthey (1833-1911), Heinrich Rickert (1863-1936) e Wilhelm Windelband (1848-1915), e de outro lado, mais firmemente inspirados em Hegel os italianos Francisco de Sanctis (1817-1883) e Benedetto Croce (1866-1952). No centro desta perspectiva, que está longe de ser homogênea, figura uma mesma recusa da pretensão positivista de fazer do método das ciências da natureza, paradigma heurístico universal. Uma proposição decisiva nesta direção éa de Dilthey, que sintetizará sua tese na construção de duas tríades, que balizariam o específico das ciências do espírito: I) intersubjetividade - memória - biografia; II) vivência - expressão - compreensão. ${ }^{17}$ É como perspectivas correlatas a estas proposições que se apresentam as obras de De Sanctis - História da Literatura Italiana, de 1870-71, e de Croce, Estética como Ciência da Expressão e Lingü̈stica Geral, de 1902, em que a literatura é tomada como forma privilegiada de expressão do espírito do tempo, como espírito e sentido da cultura. São produtos deste mesmo panorama intelectual as obras - A Filosofia do Dinheiro, de Georg Simmel (1858-1918), publicada em 1900; A Etica Protestante e o Espirito do Capitalismo, de Max Weber (1864-1920), publicada em 1904-1905; A Teoria do Romance, de Georg Lukács (1885-1971), publicada em 1914; O Outono da Idade Média, de Johan Huizinga (1872-1945), publicada em 1919; Paidéia, de Werner Jaeger (1888-1961), de 1933; A Crise da Consciência Européia, de Paul Hazard (1878-1944), de 1935; Mimesis, de Erich Auerbach (1894-1958) de 1946; Literatura Européia e Idade Média Latina, de Ernst Robert Curtius (1886-1956), de 1947. Se são muitos já os nomes, outros devem ser citados para completar o quadro - os historiadores da arte Aby Warburg (1866-1929), Alois Riege (1858-1905), Heinrich Wolfflin (1864-1945), Erwin Panofsky (1892-1968); os mestres da estilística e filologia Karl Vossler (1872-1949) e Leo Spitzer (1887-1961); os historiadores Friedrich Meinecke (1862-1954), Ernst Troeltsch (1865-1923) e Werner Sombart (1863-1936).

Como se vê, a lista não aponta para identidades. As perspectivas são diferenciadas, ou tornaram-se contrastantes com o tempo. Houve momento em que, o depois marxista Lukács, foi discípulo de Simmel e Weber. Houve tempo em que a cultura européia foi

${ }_{17}$ CoHn, G. Crítica e Resignação. São Paulo: T.A. Queiroz, 1979. pp. 17s. 
imantada pelas "ciências do espírito", que, tendo nascido na Alemanha, irradiaram-se pelo mundo. Aby Warburg criou seu Instituto em Hamburgo, que será, em 1933, transferido para Londres e que vai influenciar gerações de estudiosos dos universos simbólicos, de Ernst Cassirer a Gombrich, de Frances Yates a Carlo Ginzburg ${ }^{18}$ As lições de Simmel, na Universidade de Berlim, foram freqüentadas, ao mesmo tempo, pelo húngaro Georg Lukács e pelo espanhol José Ortega y Gassete, nos dois casos, influenciarão obras decisivas e dessemelhantes. ${ }^{19}$ Por meio de Huizinga, o grande historiador holandês, "as ciências do espírito" influenciarão a historiografia francesa dos Annales, ainda que isto não seja devidamente reconhecido. Max Weber será uma das mais decisivas matrizes do pensamento sociológico contemporâneo, de tal modo que não haverá exagero em reconhecê-las, as "ciências do espírito", como das mais decisivas marcas intelectuais do nosso tempo.

No Brasil, as "ciências do espírito" chegaram por duas vias, e frutificaram em dois momentos. Em 1939, Otto Maria Carpeaux chegou ao Brasil com uma pequena bagagem e uma ampla cultura. Em 1978, quando morreu, tinha nos apresentado a toda a cultura ocidental. Antes dele, em 1931, Sérgio Buarque de Holanda, depois de quase dois anos de vivência na Alemanha, já nos apresentara às "ciências do espírito". Na bagagem, além do texto Teoria da América, que modificado, viria a ser publicado, em 1936, como Raizes do Brasil, ele trouxe o muito que aprendeu seguindo os cursos de Meinecke, as leituras de Sombart, Simmel, Weber, Töennies, a literatura e história da arte, a poesia e as "ciências do espírito" alemãs.

As virtualidades heurísticas das "ciências do espírito" são amplas, e seus métodos e sua inspiração produziram obras em variados campos: na história da arte, na história da literatura, na sociologia, na história da cultura, na filologia. Otto Maria Carpeaux, explicitamente, inspirou-se nas "ciências do espírito" em suas obras sistemáticas - História da Literatura Ocidental, publicada entre 1959 e 1966; Uma Nova História da Música, de 1958, A Literatura Alemã, de 1964. No prefácio da primeira edição de Uma Nova História da Música ele justifica o uso das "ciências do espírito" como antídoto contra os anacronismos, e diz: "Este livro pretende evitá-los, obedecendo às linhas mestras da Geistesgeschichte ("ciência do espírito"), da ciência de Dilthey e Troeltsch, Max Weber e Croce" ${ }^{20}$ Carpeaux vai insistir na centralidade da história nas "ciências do espírito". Contudo, esta centralidade da história não significa historismo, ou historicismo, à moda

\footnotetext{
${ }^{18}$ Gombrich, E. H. Tributos. México: F.C.E., 1991. pp. 117-137; GinzBurg, C. Mitos, Emblemas, Sinais. São Paulo: Companhia das Letras, 1990. pp. 41-93.

19 Villegas, M. Los Profetas y el Mesías. México: FCE/Colégio do México, 1996.

${ }^{20}$ Carpeaux, 0. M. Uma Nova História da Música. Rio de Janeiro: José Olympio, 1967. p. XI.
} 
de Ranke ou de Meinecke. Para Carpeaux, as ciências do espírito foram salvas do "relativismo", "pela espetacular volta a Hegel, em parte por intermédio e influência do filósofo italiano Benedetto Croce". ${ }^{21}$

Aluno de Meinecke, Sérgio Buarque de Holanda também não se renderá nem ao historismo, ao qual dedicará um de seus mais notáveis trabalhos, "0 Atual e o Inatual na Obra de Leopold von Ranke", nem aos aspectos mais problemáticos da cultura alemã em que se formou. Veja-se o que diz Antonio Candido: "Sérgio respirou nesse ambiente e conheceu alguns dos seus aspectos negativos, inclusive a duvidosa caracteriologia de Ludwig Klages. Mas a retidão do seu espírito, a jovem cultura já sólida e os instintos políticos corretamente orientados levaram-no a algo surpreendente: desse caldo cultural que podia ir de conservador a reacionário, e de místico a apocalíptico, tirou elementos para uma fórmula pessoal de interpretação progressista do seu país, combinando de maneira exemplar a interpretação desmitificadora do passado com o senso democrático do presente". ${ }^{22}$

Todos sabem que em Raizes do Brasil Sérgio Buarque faz uso de categorias derivadas de Max Weber. Em seu livro de 1958, Visão do Paraíso, que retoma, e em certo sentido amplia, a discussão de Raízes do Brasil, no referente às diferenças dos processos de colonização de lusos e castelhanos, não mais aparecerá Max Weber. Por outro lado, os autores das "ciências do espírito" freqüentam em muito maior número o texto. Estão lá: Croce, Curtius, De Sanctis, Huizinga, Vossler, Wölfflin, além de Burckhardt, e não estará em erro quem colocá-lo, a este último, entre os precursores das "ciências do espírito".

Uma das virtudes mais expressivas das "ciências do espírito"éa chamada estilística, que teve seus grandes cultores na Alemanha, mas que também frutificou na Espanha, nas obras de Dâmaso Alonso por exemplo, e em seus desdobramentos fenomenológicos como em Carlos Bousoño. A tudo isto Sérgio Buarque acompanhou, apropriando-se destes instrumentos sem os vezos reducionistas de muitos de seus praticantes. Em seu grande ensaio sobre Ranke, de 1974, novamente, Sérgio Buarque vai dar mostras de sua fidelidade às suas referências maiores pela mobilização de autores como Dilthey, Burckhardt, Curtius, Croce, Max Weber, aos quais acrescenta as mais novas gerações, de algum modo, marcadas por essa referência, como Reinhart Koselleck, Max Horkheimer, Theodor Adorno, Jürgen Habermas, Ernst Bloch, Karl Löwith, entre outros nomes.

Se heterogêneo até aqui, o campo que se quer abrangido pelas "ciências do espírito",

${ }^{21}$ Carpeaux, O. M. A Literatura Alemã São Paulo: Cultrix, 1964. p. 226.

${ }^{22}$ Candido, A. "Sérgio em Berlim e Depois". In: Novos Estudos Cebrap — vol. 1, nº 3. São Paulo: julho de 1982. pp. 7-8. 
o quadro não pode deixar de ter ainda maior complexidade se se aduzir, o queé necessário, nomes como os de Walter Benjamin e Oswald Spengler. Essas novas adições ao universo das "ciências do espírito", bem entendidas, talvez, ajudem a esclarecer o seu sentido essencial. É que as "ciências do espírito" não podem ser consideradas como um campo unitário, ou unívoco, mas, como uma polifonia, como um "horizonte intelectual" que reflete o essencial da fisionomia histórica e moral de uma época. E essa época é a do fim do capitalismo liberal, da Pax Britanica, que imperou até 1914, pela emergência interdependente de processos paroxísticos - a Guerra dos 31 Anos como a chamou Hobsbawm: a Revolução Russa, as hiper-inflações, o nazi-fascismo, a crise de 1929 - 0 início da Era dos Extremos. ${ }^{23}$

As "ciências do espírito", foi dito, refletem de um lado o fim de uma certa civilização, de um certo universo mental, e de outro lado, o nascimento de uma outra hegemonia, a claramente liderada pelo capitalismo norte-americano. A percepção do fim, da crise, da decadência, como queria Spengler, foi percebida pelos mais significativos nomes das "ciências do espírito", mas as conseqüências extraídas por eles foram as mais variadas. Para Max Weber, o novo tempo que se apresentava, o da vitória da racionalidade instrumental em toda a linha significava a emergência de uma nova servidão, nosso enclausuramento coletivo numa "jaula de aço". ${ }^{24}$

Esta percepção de um universo rarefeito, dominado por forças inautênticas e destrutivas, suscitou diversas perspectivas e respostas: do nacionalismo mistificador de Spengler à escatologia milenarista do jovem Lukács, que também foi, em parte, o de Walter Benjamin. ${ }^{25}$ Diante da tragédia do mundo reificado, burocratizado, do "belo horror", como o viu Walter Benjamin, as nações reagiram: da revolta irracionalista à resignação, da adesão à perspectiva direitista à luta revolucionária, de Spengler a Max Weber, de Sombart, que chegou a aderir ao nazismo, a Lukács, que assumira desassombradamente o marxismo revolucionário.

$\mathrm{E}$, no entanto, todos esses autores partilharam do mesmo universo cultural, da mesma formação básica - são filhos, de alguma forma, das "ciências do espírito", que viveram o que Husserl disse ser, a crise da consciência européia, crise esta que vai tanto inspirar a revolução, quanto a reação. Sérgio Buarque de Holanda viveu este ambiente, formou-se pelo influxo desta tradição e soube apropriar-se desta experiência, talvez, sua melhor lição - a recusa aos reducionismos e o reconhecimento da centralidade da história para a compreensão do mundo.

${ }^{23}$ Hoвsвalvm, E. A Era dos Extremos. São Paulo: Companhia das Letras, 1995.

${ }^{24}$ COHN, G. Op. cit.

${ }^{25}$ Cf. Löwy, M. Redenção e Utopia. São Paulo: Companhia das Letras, 1989. 
0 conceito-chave para a compreensão desta "unidade com heterogeneidade", desta "dispersão-confluência concertada", que marca as "ciências do espírito", é o de "afinidades eletivas", que tem uma longa e rica tradição no pensamento ocidental, dos alquimistas medievais até Max Weber. Resumiu-a assim Michael Löwy: o conceito de "afinidades eletivas" permite "compreender (no sentido forte de verstehen) um certo tipo de conjunção entre fenômenos aparentemente díspares, dentro do mesmo campo cultural (religião, filosofia, literatura), ou entre esferas sociais distintas: religião e economia; mística e política etc" ${ }^{26}$

É armado com esta perspectiva que Sérgio Buarque desembarca no Brasil, em 1931. A partir daí, sua obra será a permanente busca da explicação de nossa singularidade como sociedade e destino, em suas variadas dimensões, como está explicitado em página confessional, rara nele - "Antigo aluno do Ginásio de São Bento, em São Paulo, além de estudante obstinado, até hoje, das histórias do Brasil..." . . 0 Obstinado estudante de história do Brasil que mobilizou neste esforço todo o mundo da cultura, que buscou compreender o Brasil no mundo e o mundo no Brasil.

\section{O Atual e o Inatual na Historiografia Contemporânea}

Jáse disse aqui, que Sérgio Buarque de Holanda foi historiador de "arquivos" e de "bibliotecas", que mobilizou tanto uma cultura enciclopédica quanto um raro apetite para 0 trabalho com fontes manuscritas, com os registros variados da cultura material de que se valem os etnógrafos. Toda esta rica e variada documentação, as amplas e diversificadas leituras, quase sempre, foram mobilizadas, em seus livrose artigos, para a compreensão do Brasil. Sua obra é demonstração do quanto as matrizes culturais adventícias, o quanto as categorias das ciências sociais podem ser úteis na apreensão das realidades nacionais. Quase sempre voltado para o estudo da realidade brasileira, algumas vezes Sérgio Buarque buscou temas não nacionais e aí, também, foi esplêndido. Éo caso de seu artigo sobre Ranke, " 0 Atual e o Inatual na obra de Leopold von Ranke".

Nascido na Turingia, em 1795, nobilitado em 1865, transformado em Altvater da historiografia prussiana, Ranke nunca foi apenas isto, enem mesmo isto, inteiramente, já que sua perspectiva, antes de ser prussiana foi, sobretudo, européia. Naquele artigo, Sérgio Buarque vai dar mostras do seu extraordinário talento como crítico da historiografia

${ }^{26}$ Löwr, M. Redenção e Utopia. São Paulo: Companhia das Letras, 1989. p. 16.

${ }^{27}$ HOLANDA, S. B. de. Op. cit., 1996, p. 318. 
e como detentor de cultura enciclopédica e atualizada. Tais características são a mais explícita manifestação da riqueza do seu universo intelectual. Desde logo, registre-se que há no texto em questão uma espécie de retomada das fontes formativas do pensamento de Sérgio Buarque adquiridas na Alemanha, e sintetizadas nos nomes de Dilthey, Burckhardt, Croce, Weber, Meinecke, Curtius e que formam aquela mescla de aproximações, de "afinidades eletivas", entre as "ciências do espírito" e o historismo, que não sendo apenas correntes alemãs, são alemãs em grande medida. 0 historismo, disse Meinecke, teve na Alemanha, com Herder, Goethe e Ranke, sua pátria espiritual. Como afirmou Meinecke, "o historicismo não é mais que a aplicação, à vida histórica, dos novos princípios vitais descobertos pelo grande movimento alemão que vai de Leibniz à morte de Goethe" 28 Disse Curtius, citado por Sérgio Buarque: "o historismo não é uma teoria científica e sim um modo de ver e ser, surgido no universo mental de Hegel e Ranke, de Nietzsche e Jacob Burckardt, e que só nele poderia aparecer" [...] "como forma de vivência, que atuara já sobre Goethe e Hegel, e seria ininteligível sem Herder, o historismo é inseparável da vida espiritual germânica". ${ }^{29}$

Foi na Alemanha, entre 1929 e 1931, que Sérgio Buarque absorveu esses princípios. Dessas lições ele vai armar um universo conceitual que lhe valerá tanto para o trabalho de historiador das coisas do Brasil quanto para os estudos literários. Mas, a grande utilização dessas idéias demorará a se materializar integralmente. É com o texto de 1974, cinqüienta e três anos depois de sua volta ao Brasil, que Sérgio vai explicitar todo o seu notável conhecimento do apreendido na Alemanha e do desenvolvido a partir daí, sobre as "ciências do espírito" e sobre o historismo.

0 século XIX, século da história, como foi chamado, século dos grandes historiadores, foi marcado pela obra de Ranke. Seus discípulos e entusiastas, além de seus críticos, preenchem um capítulo decisivo da história da historiografia no século XIX, como se vê nos livros de Fueter e Gooch. ${ }^{30}$ Fueter é autor de uma História da Historiografia, cuja primeira edição é de 1911, e vai tanto valorizar Ranke, por sua posição não estreitamente nacionalista, quanto vai apontar seu mais decisivo defeito que, para Fueter, seria a unilateralidade com que incorpora as fontes documentais. ${ }^{31}$ De seu lado, Gooch buscou mostrar as diferenças entre Ranke e Niebuhr, que ele vê como o verdadeiro criador

\footnotetext{
${ }^{28}$ MeInecke, F. El Historicismo y su Genesis. México: FCE, 1982. p. 12.

${ }^{29}$ Holanda, S. B. de. "O Atual e o Inatual na Obra de Leopold von Ranke". In: Revista de História nº 100, vol. L, Ano XXV. São Paulo: outubro-dezembro, 1974. pp. 454s.

${ }^{30}$ FuETER, E. Historia de la Historiografia Moderna. Buenos Aires: Editorial Nova, 1953; Gooch, G. P. Historia e Historiadores en el siglo XIX. México: FCE, 1942.

${ }^{31}$ FuETER, E. Op. cit., 1942., pp. 148-168. (Vol. 2).
} 
da historiografia moderna. Berthold Georg Niebuhr, sueco (1776-1831), fora por excelência o criador, na verdade, da historiografia de corte romântico, inspirada em Herder. Para Gooch, o traço característico de Ranke, o que o distinguia da tradição inaugurada por Niebuhr, é sua perspectiva não "nacionalista", sua busca dos fundamentos da história européia, entendida como fusão de culturas. ${ }^{32}$

A obra de Ranke, o historismo, tal como ele o praticou e entendeu, vai ser o ponto de partida das "ciências do espírito", seja em sua versão alemã, com Dilthey e Max Weber, seja em sua versão italiana com Croce. Diz Le Goff: "Dilthey começou por criticar os conceitos fundamentais do historicismo de Humboldte Ranke: alma popular (volksseele), espírito do povo (volksgeist), nação, organismo social, são para ele conceitos "místicos", inúteis para a história. Depois pensou que era possível o conhecimento das ciências do espírito - nelas compreendendo a história - porque a vida se objetiva em instituições como a família, a sociedade civil, o Estado, o direito, a arte, a religião, a filosofia" [...] "Acreditava que a "visão histórica do mundo era a libertadora do espírito humano a quem tirava as últimas cadeias, que as ciências da natureza e a filosofia não tinham tirado". "Toda a crítica do historicismo, do fim do século XIX e início do XX, é ambígua. Procura mais ultrapassar o historicismo, como acabamos de ver com Dilthey, que renegá$10 "{ }^{33}$ Em apreciação equilibrada, Georges Lefebvre reconheceu em Ranke duas virtudes decisivas - sua extraordinária erudição e a afirmação da importância da documentação, sobretudo daquela decorrente de fontes diplomáticas e estatais. ${ }^{34}$ Este mesmo aspecto, que mereceu o elogio de Lefebvre, foi visto por outros com reserva já que Ranke nem sempre foi capaz de submeter à crítica a documentação utilizada do ponto de vista de seus interesses e comprometimentos ideológicos.

De qualquer modo, Ranke buscou não negligenciar qualquer aspecto ou nação, porque "cada povo é imediato com Deus", 35 e neste sentido foi capaz de, sendo luterano, escrever uma história dos papas na época moderna, que tanto não desagradou aos católicos, quanto mereceu elogios de protestantes ingleses, como se vê em Lord Thomas Macaulay, em seu Ensaios Históricos. ${ }^{36}$ Vivendo tanto as tensões da unificação bismarckiana, quanto a expansão do II $^{\circ}$ Reich, Ranke jamais foi nacionalista xenófobo como seu rival Droysen ou seu discípulo Sybel. Escreveu páginas de grande compreensão sobre Portugal, Espanha,

${ }^{32}$ Gooch, G. P. Op. cit., 1942. pp. 83-136.

${ }^{33}$ Le Gofr, J. "História". In: Romano, R. (Org.). Enciclopédia Einaudi. Lisboa, Imprensa Nacional, 1984. pp. 208209 (vol. I).

${ }^{34}$ Lefebvre, G. El Nacimiento de la Historiografia Moderna. Barcelona: Roco, 1974. p. 276.

${ }^{35}$ Id. ib., p. 278.

${ }^{36}$ MacauluY, Lord T. B. Ensaios Históricos. São Paulo: Companhia Editora Nacional, 1940. pp. 253-292. (Vol. 2). 
França, Inglaterra, buscando afirmar aquela que foi sua grande tese - a da fusão dos povos romano-germânicos na constituição da Europa e da modernidade. ${ }^{37} \mathrm{~A}$ influência de Ranke no século XIX foi decisiva, tanto na Alemanha quanto fora dela. Seus desdobramentos far-se-ão, como disse Le Goff, mediante deformações positivistas (na França e nos Estados Unidos) ou idealistas, como no caso de Croce, na Itália.$^{38}$ Os discípulos de Ranke, Georg Waitz (1813-1886) e Heirich von Sybel (1817-1895), vão codificar os procedimentos metodológicos desenvolvidos pelo mestre, e estes princípios vão marcar todas as grandes obras da Teoria da História a partir daí. Em 1889, E. Bernheim publica - Compêndio de Método Histórico, que dá início à publicação de uma série de tratados: 1902, A Propósito da Teoria da Metodologia, de Edouard Meyer; 1921, Introdução ao Estudo da História, de Wilhelm Bauer. ${ }^{39} \mathrm{Na}$ França, a lição de Ranke virá por meio de Bernheim. Dizem Langlois e Seignobos, no tratado clássico, de 1905, Introdução aos Estudos Históricos: "Ernst Bernheim, professor da Universidade de Greifswald, rebuscou quase todos os escritores modernos sobre o método histórico, agrupou-os em quadros cômodos e, em grande parte, absolutamente inéditos, grande número de observações e referências criteriosamente selecionados. Seu Lebrbuch der bistorichen methode (Leipzig, 1984; in $8^{\circ}$ ) condensa, segundo os moldes dos lehrbücher alemães, a literatura especial do assunto nele versado. Não nos move, pois, o desejo - nem para isso temos razões - de refazer a obra tão proficientemente executada por Bernheim" 40

É sobre esse Ranke, tão poderoso, no século XIX, e aparentemente inatual no século XX, que Sérgio Buarque de Holanda, em 1974, num Brasil tão anêmico de debates metodológicos consistentes em história, empreende seu mais vigoroso texto de crítica historiográfica, sua obra prima neste campo. Há uma estratégia expositiva no ensaio de Sérgio Buarque de Holanda - "O Atual e o Inatual na Obra de Leopold von Ranke" - que não sendo inédita tem economia complexa e sutil. Trata-se do fato de que discutindo a obra de Ranke, defendendo-o de certas críticas, Sérgio acaba por formular uma espécie de súmula do seu próprio ponto de vista sobre as especificidades do ofício do historiador. Esse texto, de 1974, e outro, de 1973, "A Doença Infantil da Historiografia", produzidos por um homem já com mais de setenta anos, depois de mais de cinqüenta anos de presença na vida intelectual brasileira, são como o testamento intelectual de uma vida dedicada aos estudos históricos, e evocam os livros de Marc Bloch, Introducão à História, de 1949,

\footnotetext{
${ }^{37}$ Ranke, L. von. Pueblos y Estados em la Historia Moderna. México: FCE, 1986.

${ }^{38}$ LE GoFf, J. Op. cit., p. 208.

39 Colungwood, R.G.A Idéia de História. Lisboa: Presença, s.d. pp. 272-275; Bauer, G. Introducción al Estudio de la Historia. Barcelona: Bosch, 1957.

40 LangloIs, C.; Seignobos, C. Introdução aos Estudos Históricos. São Paulo: Renascença, 1946. p. 11.
} 
e Combates pela História, de Lucien Febvre, de 1953, também eles a síntese reflexiva de mestres da historiografia.

"0 Atual e o Inatual na Obra de Leopold von Ranke", publicado na Revista de História da USP em 1974, em seu número 100, foi publicado mais duas outras vezes: em 1979, como introdução ao volume dedicado a Ranke para a coleção Grandes Cientistas Sociais, da Ática, coordenado por Florestan Fernandes; e em 1996, no Livro dos Prefácios, que reuniu os prefácios de Sérgio Buarque para livros de terceiros, de história e literatura. Sobre o texto em pauta disse Francisco Iglesias: "Este estudo é talvez o melhor de todos da coleção e um dos momentos máximos da crítica historiográfica do país". ${ }^{41}$ Também sobre o mesmo ensaio disse José Guilherme Merquior: "a introdução de Sérgio Buarque de Holanda ao volume Ranke [...], a meu conhecimento, uma das mais lúcidas e cultas discussões do historismo, em qualquer língua...". 42

0 exemplo de Sérgio Buarque, a altivez com que dialoga, em pé de igualdade, com as grandes correntes intelectuais internacionais, não é freqüente entre nós. Mais infreqüente ainda é o tom com que Sérgio Buarque modula o seu discurso - não há acanhamento ou arroubos neófitos, não há servilismos ou reverências indevidas - sem pedir desculpas, com segurança, ele age como se natural fosse, e deveria ser, que a periferia participasse dos debates das grandes questões culturais com as mesmas credenciais que 0 centro, pela simples e decisiva razão que também a nós estes debates dizem respeito. Seé raro, não é único o exemplo, que há outros intelectuais brasileiros, que se reivindicam participantes qualificados de debates importantes, como, por exemplo, o realizado pela Universidade Estadual do Rio de Janeiro, o V Colóquio UERJ, sobre Erich Auerbach (1994), em que a participação dos brasileiros foi de alta qualidade. ${ }^{43}$

0 texto de Sérgio Buarque que se quer discutir aqui é, direta e imediatamente, uma crítica ao historismo, a esta escola historiográfica, em grande medida, decorrente do método e das obras de Ranke (1795-1886), grande historiador alemão, que produziu obra imensa e amplamente influente. É com Ranke que, efetivamente, se consolidarão os métodos e técnicas, uso e crítica das fontes que postularam atribuir à história o status de ciência. Se esseé objetivo imediato do texto de Sérgio Buarque, sua fatura e implicações vão além disso e são, de um lado, um balanço do debate historiográfico, desde o final do século XIX, e, de outro lado, a explicitação do que deve ser considerado vivo e o que deve ser abandonado no fazer dos historiadores. Sérgio Buarque faz balanço do historismo, ou

\footnotetext{
${ }^{41}$ IGLÉSIAS, F. Op. cit., p. 39.

${ }^{42}$ Merquior, J. G. 0 Argumento Liberal. Rio de Janeiro: Nova Fronteira, 1983. p. 236.

${ }^{43}$ Rochi, J. C. de C. (Org.). V Coloquio UERJ - Erich Auerbach. Rio de Janeiro: Imago, 1994.
} 
historicismo que é termo que ele entende menos adequado que o anterior. Sua visão, ampla e informada, abarca as diversas dimensões e sentidos em que a escola desdobrouse, centrando-se na figura de Ranke a partir da qual ele busca aferir tanto o sentido essencial da proposta da escola, quanto seus desdobramentos e legado. A questão do historicismo é complexa porque são vários os sentidos e usos do termo. Jerzy Topolsky a viu assim: "o conceito de historicismo é um dos mais ambíguos na metodologia da história e seus principais significados podem ser enumerados assim: a) Historicismo geral; b) Historicismo absoluto; c) Historicismo tal como definido por Popper; d) Historicismo como sinônimo de "filosofia da história"; e) Historicismo existencial; f) Historicismo dialético. ${ }^{44}$

Ao mesmo tempo que Sérgio publicava seu texto, Arnaldo Momigliano, o grande historiador italiano, participava de evento em Londres, no Instituto Warburg, em 1974, cujo propósito era "revisitar" o historismo. 0 resultado disto é o texto - O Historicismo Revisitado - publicado na Holanda, em 1974, e cuja comparação com o texto de Sérgio Buarque permite avaliar seus propósitos e envergadura. Também com o texto de Momigliano estamos diante de um trabalho de mestre da erudição e da longa reflexão sobre a historiografia. A interrogação de Momigliano tem pontos de contato com a de Sérgio Buarque, por exemplo, na recusa de ambos em aceitar a "história estrutural" como correção ao legado historista. Diz Momigliano: "Não há esperança de que o estruturalismo nos salve das dificuldades do historicismo". ${ }^{45}$ E Sérgio Buarque afirma: "os modernos estruturalismos dos lingüistas, dos economistas ou dos antropólogos. [...] Quase sempre resultam de teorias elaboradas numa perspectiva estática, quando muito estável, que não se integram no tempo senão com dificuldade. Nessas condições podem tornar-se tão incompatíveis com o processo histórico que é o caso de perguntar se a expressão "história estrutural" não encerra um contra senso". ${ }^{46}$ No geral, contudo, é mais ampla a visão de Sérgio Buarque que, ao interrogar o legado de Ranke para a historiografia acaba discutindo os elementos que teriam o condão de manter viva e atual a atividade historiográfica.

É essa também, em parte, a motivação do texto de Momigliano. Ele busca responder à pergunta sobre o sentido, sobre a especificidade da historiografia reconhecendo, aí, a importância do historismo. Para ele, a grande contribuição do

\footnotetext{
${ }^{44}$ Topolsky, J. Metodologia de la Historia. Madrid: Cátedra, 1982. p. 110.

${ }^{45}$ Momigliano, A. Ensayos de Historiografia Antigua y Moderna. México: FCE, 1997. p. 306.

${ }^{46}$ Holanda, S. B. de. Op. cit., 1974, pp. $475 \mathrm{~s}$.
} 
historismo teria sido a explicitação da historicidade seja do objeto, seja do sujeito da reflexão historiográfica. Dizele: "o historicismo éo reconhecimento de que cadaum de nós vêos acontecimentos passados dado um ponto de vista determinado ou pelo menos condicionado por nossa própria cambiante situação individual na história" ${ }^{47}$ Esta visada teórica, de resto correta e necessária no referente à historiografia, tem, por outro lado, um inconveniente decisivo queé a admissão de um "relativismo puro" que, segundo Momigliano, éindefensável: "A história da historiografia como qualquer outra investigação histórica, tem o propósito de discernir entre verdade falsidade" ${ }^{48} 0$ propósito de Momigliano, ao revisitar o "historicismo", é apontar para o "beco sem saída" que decorreria de se levar até as últimas conseqüências aquela espécie de "suspension of desbilief" que caracterizaria o historicismo.

Sérgio Buarque de Holanda, a partir da mesma motivação - revisitar o historismo para avaliar a atualidade de seu legado - vai mais longe. Seu propósito, desde logo, traz perspectiva rigorosamente dialética. Reconhecendo as limitações e o obsoleto de certos componentes da obra de Ranke, Sérgio Buarque buscou caminho mais compreensivo e complexo para abordá-la. Diz ele: "É inegável porém que uma constante meditação sobre problemas do seu ofício, levando-o a não se conformar tranqüilamente com idéias então dominantes, abriu-lhe os olhos para a possibilidade de soluções que estariam mais fora do alcance de outros estudiosos. Com isso, com seu exemplo, às vezes com sugestões suas, terá contribuído para que entre seus herdeiros e sucessores permanecesse a mesma capacidade de meditação e de insatisfação. Seria explicável, assim, o fato de que existe até hoje muita coisa de atual em sua inatualidade". ${ }^{9}$

Desde logo, é preciso reconhecer que esta maneira de formular a questão lembra procedimentos semelhantes decisivos da história do pensamento: a crítica da economia política de Marx, que tem a mesma estratégia expositiva, isto é, a crítica como apropriação e re-significação de certos aspectos das teorias consideradas; e, sobretudo, o livro de Benedetto Croce - O Vivo e o Morto da Filosofia de Hegel - de 1907, republicado em 1912 com apêndice bibliográfico utilíssimo até hoje, e que é a referência explícita do ensaio de Sérgio Buarque..$^{50}$

Velho leitor de Croce, Sérgio Buarque, certamente, aproveitou sua estadia na Itália para voltar ao velho mestre napolitano. Este acabava de morrer, (1952), quando Sérgio inicia sua fase italiana, que vai durar até 1954. É neste período, em contato com

\footnotetext{
47 Momigliano, A. Op. cit., 1997, p. 304.

${ }^{48}$ Id. ib., p. 310.

${ }^{49}$ HoLANDA, S. B. de. Op. cit., 1974, pp. 474s.

${ }^{50}$ Croce, B. Lo Vivo y lo Muerto de la Filosofia de Hegel. Buenos Aires: Imán, 1943.
} 
os arquivos e as bibliotecas italianas que ele inicia seu livro sobre a Literatura Colonial Brasileira, de que só foi publicado um fragmento, em 1991, com o título de Capítulos da Literatura Colonial. Planeja também, nesse período, o livro que ele dá notícia de estar preparando, em 1956 - A Era do Barroco no Brasil (cultura e vida espiritual nos séculos XVII e XVIII) ${ }^{51}$ - e que é explícita evocação do livro de Croce, Storia dell'etá Barrocca in Italia, de 1929. Desta estadia em Romaétambém o ensaio - "Acontribuição italiana para a formação do Brasil" - publicado na Revista Ausonia, vol. IX, n 5 , setembro-outubro de 1954, em mímeo organizado por ele para apresentar aos italianos um pouco da cultura brasileira. ${ }^{52}$

Sérgio Buarque de Holanda escolhe uma grande corrente intelectual, e dentro dela seus maiores expoentes, seu "Altaver", como o disse Momigliano, e a partir deste "patriarca", de sua grandeza e de suas limitações, empreende um balanço do essencial da historiografia contemporânea do ponto de vista dos procedimentos metodológicose "modos de fazer" que deveriam presidir a sua prática.

É no velho e inatual Ranke que Sérgio Buarque vai identificar certas teses que seriam atuais e indispensáveis para a historiografia. Ranke combateu 0 determinismo na história, a religião do progresso. ${ }^{53}$ Em sua historiografia não há lugar para o fervor nacionalista, para o preconceito religioso, para o positivismo, que alguns desavisadamente lhe imputaram. Sua perspectiva, viu assim Dilthey, era do "incomparável mestre da história encarada com objetividade e universalidade". ${ }^{44}$ É de 0tto Hintze a tese que Sérgio Buarque escolhe - "a tradição fecunda e gloriosa do historismo que, infenso, por sua natureza, a pretensões dogmáticas, pode renovar-se sem dificuldades maiores". ${ }^{55}$ Renovar-se sem dificuldades maiores, porque infenso aos dogmatismos, eis um grande legado do historismo, que Sérgio Buarque quer afirmar, ao lembrar alguns dos temas que decorrentes dos desdobramentos do historismo - os fatores conscientes e inconscientes, o individual e o coletivo, a continuidade e a descontinuidade são decisivos no repertório historiográfico contemporâneo. ${ }^{56}$

\footnotetext{
¿1 Candino, A. Introdução aos Capítulos da Literatura Colonial. In: Holanda, S. B. de. Capítulos da Literatura Colonial. São Paulo: Brasiliense, 1991. p. 10.

${ }^{52}$ Holavds, S. B. de. A contribuição italiana para a formação do Brasil. Edição bilíngüe, Florianópolis: Editora UFSC, 2002.
}

53 HoLndNa, S. B. de. Id. ib., 1974, p. 473

Holund, S. B. de. Id. ib., 1974, p. 438

55 HoLnd, S. B. de. Id. ib., 1974, p. 477.

${ }^{56}$ HolnND, S. B. de. Id. ib., 1974, p. 478. 
Sérgio Buarque, que acompanhava atentamente 0 desenvolvimento da historiografia, que se manteve atualizado sobre as novidades no campo das ciências sociais, do estruturalismo à Escola de Frankfurt, da École des Annales aos primeiros tempos da Nouvelle Histoire, não hesitou em buscar no historismo o campo capaz de possibilitar ressaltar o essencial do ofício do historiador. É que o historismo contempla 0 universo completo das grandes questões da historiografia: a afirmaçã̃o das fontes como requisitos essenciais ao discurso historiográfico; a crítica das fontes; a descoberta essencial, que está em Ranke, de que o discurso historiográfico se legitima, pela compreensão que a história só é apreensível pelo reconhecimento da dialética entre as singularidades e as semelhanças, entre o único e as repetiç̃es, as similaridades e as conexões. ${ }^{57}$

Esta idéia, a tese de que a história é sempre continuidade e ruptura, 0 mesmo e 0 outro, é a contribuição decisiva do historismo de Ranke, aquilo que lhe garante atualidade e que forma, junto com mais duas outras questões, o núcleo essencial das aporias que caracterizam o campo da historiografia. Estas aporias são: a que deriva da tese de Croce de que "toda história é história contemporânea", e a que foi explicitada por Lucien Febvre e que pode ser enunciada como a exigência da interdição do anacronismo. É então como um conjunto de aporias que se constitui o campo historiográfico contemporâneo: a históriae sempre continuidade e ruptura; a história é sempre história contemporânea; a história sendo sempre história contemporânea, não pode exigir menos que a interdição de todo o anacronismo, mesmo que isto seja, efetivamente, impossível.

Constrangidos por essas tensões constitutivas, inescapáveis aos historiadores, cabem duas providências: de um lado, reconhecer a radicalidade do desafio posto ao seu ofício, e de outro lado, reconhecer que a maneira possível de enfrentar este desafio, aquilo que efetivamente caracteriza a história, é o fato de que a história "pretende compreender o mundo no passado e por meio dele". ${ }^{58}$ Isto é, que tudo o que se disser sobre o passado, só tem legitimidade histórica, quando estiver baseado em fonte coeva, quando for contemporânea do fato, realidade que se quer compreender.

\footnotetext{
${ }^{57}$ HoLANDA, S. B. de. Id. ib., 1974, p. 445.

${ }^{58}$ Huizinga, J. El Concepto de la Historia. México: FCE, 1980. p. 92.
} 